\section{G175(P) THE IMPACT OF CLOSE LIAISON WITH SOCIAL WORK ON HEALTH ASSESSMENTS IN LOOKED AFTER CHILDREN}

S Wilson, R Gibbs, I Young. Paediatrics, Borders General Hospital, Melrose, UK

\subsection{6/archdischild-2018-rcpch. 170}

Aims Looked after children (LAC) are a vulnerable group who often have significant health needs. Scottish government guidance requires that they 'should have a health assessment within 4 weeks of notification to the Health Board'. The social work department are responsible for informing the health board as soon as the child becomes accommodated. The target identified was within two weeks. Our aim was to assess the impact of close liaison with social work and careful monitoring of our LAC database on the timings of the health needs assessments in LAC.

Methods Data was collected retrospectively from a database of LAC. Twenty children were selected at random from the date the health board was informed: between July 2015 to December 2015. Following this, the database was enhanced and liaison was done within the multi-disciplinary team to ensure there was regular monitoring of the children on it. Education with social work addressed early notification as a priority, with emphasis on timely consent from parents and the importance of the child's attendance at these appointments. The audit was repeated with data between November 2016 and August 2017 (tables 1 and 2).

Results

\begin{tabular}{lll}
$\begin{array}{l}\text { Abstract G175(P) } \\
\text { LAC team notified }\end{array}$ & Table & Timeframe from accomodation until \\
\hline Audit & Mean (days) & Median (days) \\
\hline 2015 & 17 & 11 \\
$2016 / 2017$ & 10 & 3 \\
\hline
\end{tabular}

$\begin{aligned} & \text { Abstract G175(P) Table } 2 \\
& \text { team until medical }\end{aligned}$
\begin{tabular}{llllll}
\hline Audit & $\begin{array}{l}\text { Total number of } \\
\text { children }(\mathbf{n})\end{array}$ & $\begin{array}{l}\text { Within } \\
4 \text { weeks }(\mathbf{n})\end{array}$ & $\begin{array}{l}\text { Within } \\
6 \text { weeks }(\mathbf{n})\end{array}$ & $\begin{array}{l}\text { Mean } \\
\text { (days) }\end{array}$ & $\begin{array}{l}\text { Median } \\
\text { (days) }\end{array}$ \\
\hline 2015 & 20 & $5(25 \%)$ & $8(40 \%)$ & 50 & 50 \\
$2016 /$ & 19 & $7(37 \%)$ & $13(68 \%)$ & 49 & 35 \\
2017 & & & & & \\
\hline
\end{tabular}

Conclusion Health assessments in accommodated children should be a priority for health professionals. Close liaison with social work has shown a significant improvement in the average time for the health board to be informed of newly accommodated children. Effective use and monitoring of our LAC database within the multidisciplinary team has improved the number of children seen within four weeks. There appears to be ongoing issues around consent from parents and failure to attend initial appointments. We are now considering other means of assessing the child's health needs ahead of the medical.

\section{G176(P) SPECTRUM OF CHILDHOOD AND ADOLESCENT NEURODEVELOPMENTAL CASELOAD IN A COMMUNITY CHILD HEALTH CLINIC: EXPERIENCE FROM A MID- EASTERN SCOTTISH REGION}

MO Ogundele. Community Paediatrics Unit, Glenwood Health Centre, Glenrothes, UK

\subsection{6/archdischild-2018-rcpch.171}

Community Child Health $(\mathrm{CCH})$ is the branch of Paediatrics that specialises in childhood developmental-behavioural problems, such as ADHD, ASD, developmental delays emotional and behavioural issues. These problems are being increasingly recognised worldwide but the healthcare services available for addressing them are largely deficient.

Objectives We aimed to analyse the range of neurodevelopmental, behavioual and emotional (NDBE) disorders among children and young people seen in two $\mathrm{CCH}$ clinics of a Mid-Eastern Scottish NHS Trust over a 12 month period.

Methods A retrospective review of all patients seen in the outpatient clinics between June 2016 and May 2017 was carried out. The study was completed as part of an audit and the Clinical Governance strategies of the NHS Fife.

Results A total of 543 patients (28.1 per 1000 children's population), aged between 2 months and 18 years 6 months (Mean 104 months), 72\% males, presented with an average of 3 NDBE conditions (ranging from 1 to 8), also under the care of average of 2 additional professionals.

The largest caseload of patients (46\%) were seen in Summer. The highest proportion of children (30\%) were from the most deprived 20\% (Quintile 1) areas. The largest age-group of the patients (47\%) were school-age (5-9 years) children.

There was a statistically significant relationship between the number of diagnosis and the number of professionals involved in the management of each patient. Commonest diagnosed NDBE categories were difficulties with Behaviour (45\%), Sleep (30\%), Social Communications (27\%), DCD (24.5\%), Sensory processing (22\%), LD (19\%), ADHD (17\%), SALD (17\%). ASD accounted for (13\%) and GDD was $12 \%$.

The commonest multi-agency professionals involved were the OT (33\%), SALT (26\%), HV (18\%), CAMHS (17\%), Educational- (16\%) and Clinical-Psychologists (15\%).

Conclusion This study highlights the significant public health importance of childhood Neurodevelopmental disorders involving over $2 \%$ of the population and requiring high levels of integrated multi-professional involvement because there is a high level of symptoms sharing and co-morbidity across various disorders. The high risk of future mental health problems in adulthood demands a corresponding long-term follow-up and surveillance of children with NDBE problems.

\section{G177(P) SUDDEN INFANT DEATH SYNDROME IN TWINS - IS THERE A RISK TO THE SURVIVING TWIN?}

R Lee-Kelland, F Finlay. Community Child Health, Royal United Hospital, Bath, UK

10.1136/archdischild-2018-rcpch.172 